\title{
A Stochastic Approach for Automatic and Dynamic Modeling of Students' Learning Styles in Adaptive Educational Systems
}

\author{
Fabiano Azevedo DORÇA ${ }^{1}$, Luciano Vieira LIMA ${ }^{2}$, \\ Márcia Aparecida FERNANDES ${ }^{1}$, Carlos Roberto LOPES $^{1}$ \\ ${ }^{1}$ Faculty of Computer Science, Federal University of Uberlândia (UFU) \\ Campus Santa Mônica - Bloco 1B - Sala 1 B148 \\ Av. João Naves de Ávila, 2.121 - Bairro Santa Mônica, CEP 38400-902 - Uberlândia/MG, Brazil \\ ${ }^{2}$ Faculty of Electrical Engineering, UFU \\ e-mail: \{fabiano, marcia, crlopes@facom.ufu.br\},vieira@ufu.br
}

Received: January 2012

\begin{abstract}
Considering learning and how to improve students' performances, an adaptive educational system must know how an individual learns best. In this context, this work presents an innovative approach for student modeling through probabilistic learning styles combination. Experiments have shown that our approach is able to automatically detect and precisely adjust students' learning styles, based on the non-deterministic and non-stationary aspects of learning styles. Because of the probabilistic and dynamic aspects enclosed in automatic detection of learning styles, our approach gradually and constantly adjusts the student model, taking into account students' performances, obtaining a fine-tuned student model. Promising results were obtained from experiments, and some of them are discussed in this paper.
\end{abstract}

Keywords: dynamic student modeling, learning styles, probabilistic student model, adaptive educational systems, e-learning.

\section{Introduction}

Learning Styles (LS) and their effects on learning processes are carefully exposed by Coffield et al. (2009). Their related instructional strategies have been massively studied in the new learning space introduced by the Internet, where many researchers point out that students learn in different ways and linking LS to appropriate learning resources is an important stimulus for the learning process. Some researches reveal that students' performance is improved if the learning environment provides adaptivity concerning LS (Haider et al., 2010; Graf et al., 2008; Kinshuk et al., 2009; Alfonseca et al., 2006; Graf et al., 2009; Felder and Silverman, 1988; Graf et al., 2010). Based on these arguments, several research works dealing with incorporating LS in Adaptive Educational Systems (AES) have been conducted. According to Kinshuk et al. (2009), the field of LS is complex and many questions are still open, including a clear definition of LS. Investigations have been conducted on relating LS characteristics to learning objects characteristics. 
In order to provide adaptivity, students' LS have to be known firstly. However, traditional approaches for acquiring students' LS in AES are inefficient.

Price (2004) analyzes the uncertainty aspect of the Index of Learning Styles Questionnaire (ILS) by identifying inconsistencies between its results and students' behavior.

Roberts (Roberts and Erdos, 1993), as well as Price, analyzes this kind of instrument and the problems related to it. Castillo et al. asserts that the information about the students' LS acquired by psychometric instruments encloses some degree of uncertainty (Castillo et al., 2005).

Therefore, investigations are conducted towards improving the process of LS detection. According to Kinshuk et al. (2009), it can be done by enhancing LS questionnaires through diminishing the influence of factors that hinder an accurate estimation and by using an automatic approach for identifying LS based on students' behavior in an on-line course.

Automatic approaches for diagnosing LS are free from the problem of inaccurate selfconceptions of students (Graf and Lin, 2007). Therefore, many approaches for automatic detection of students' LS have been proposed. However, in general, they present problems which make them either inefficient or difficult to be implemented, implanted and used, as pointed out in Section 2.

According to Graf and Lin (2007), one of the problems with automatic approaches is to get enough reliable information to build a robust student model (SM). We believe that stochastic modeling techniques can cope with this problem, specifically Markov Chains. In this context, we propose a stochastic approach based on Markov Chains for automatic and dynamic modeling of students' LS in AES, which detects and precisely adjusts students' LS based on non-stationary and non-deterministic aspects of LS, which may change during the learning process (non-stationary) in an unexpected and unpredictable way (non-deterministic) (Graf and Kinshuk, 2009; Graf et al., 2010). Consequently, our approach enables AES to incrementally learn about students' LS and update them if they are changed over time. A learning style questionnaire, like ILS questionnaire, may be applied in order to initialize the SM, but it is not compulsory.

Our approach is based on the Felder and Silverman Learning Styles Model (FSLSM) (Felder and Silverman, 1988). Section 3 exposes some important reasons why the FSLSM has been chosen. According to Graf and Kinshuk (2009, 2010a), the FSLSM uses the concept of dimensions, and therefore describes LS precisely. A very important characteristic of FSLSM to our work is that it uses scales instead of defined types. In this way, the strength of each LS is finely measured (Felder and Silverman, 1988). Therefore, our approach aims to gradually tune students' LS stored in SM during the learning process. Another important aspect of FSLSM is that it considers LS as tendencies and therefore, it takes into account the fact that students may act differently according to specific situations, in a non-deterministic way, as pointed out by Kinshuk et al. (2009), Graf and Kinshuk (2009). Thus, we consider students' LS as probabilities in the four-dimensional FSLSM model, as depicted in Section 4. As a result, our approach gradually, constantly and stochastically adjusts the SM using a set of rules that detect which LS should be updated considering the students' performances at a specific moment. As a consequence, 
the SM effectively converges towards the students' LS, as shown in Section 5. Finally, Section 6 presents conclusions and future works.

\section{Related Works}

A diversity of approaches for automatic detection of LS has been proposed, as it can be seen in Graf and Liu (2008), Graf and Kinshuk (2010b), Castillo et al. (2005). In general, these approaches use deterministic inference systems for detecting students' behavioural patterns. These systems infer the LS based on students' actions. One of the problems with these systems is the uncertainty, difficulty and complexity of developing and implementing rules that are able to infer LS effectively through students' actions and to treat students' behaviour as evidences and not as possibilities. Besides, in some systems like AHA! (De Bra et al., 2006), these rules must be defined by the tutor, making the system more difficult to be used.

More complex approaches can be seen in Kelly and Tangney (2005), García et al. (2007), Carmona et al. (2008), Cabada et al. (2009), Zatarain-Cabada et al. (2009), Zatarain et al. (2010), Carmona et al. (2007). These approaches use learning machine techniques, such as Bayesian and Neural Networks. Some of the problems with these approaches are both high complexity and computational cost, which are thought to be serious concerns when considering a high number of students using the AES simultaneously. Besides, in general, these approaches are highly coupled, either to the system or to the whole teaching process, making them harder to be re-used in other systems. In some of these approaches, once acquired, the students' LS remain the same throughout the entire learning process (Castillo et al., 2005).

Another well-known problem with these approaches is the complication generated by concept drift and concept shift (Castillo et al., 2005). It is well-explained by Castillo et al. (2005) that, as a rule, supervised learning assumes the stability of the target concept. Therefore, in many real-world problems, when data is collected over an extended period of time, the learning task can be complicated by changes in the target concept. This problem is known as concept drift. Concept drift scenarios require incremental learning algorithms, which are able to adjust quickly to drifting concepts. Depending on the rate of the changes, we can distinguish concept drift (gradual changes) from concept shift (abrupt changes; Castillo et al., 2005). In the context of our work, they occur either because the acquired LS need to be adjusted or because the students' LS are changed for some unknown reason. As it is well known, during the interactions with the system, students can change their preferences for other kinds of learning resources which no longer match with their previously determined LS (Castillo et al., 2005; Graf and Kinshuk, 2009; Graf et al., 2010). As stated by Graf et al. (2009), LS, as described by FSLSM, are considered to be "flexibly stable", which means that they are relatively stable but can change over time, for example, if learners train their weak learning preferences.

In this scenario, adaptive decision models, which are able to better adapt to students' LS, are desirable. In this context, we believe that our approach brings advantages due to the following specific features: 
- it considers that not only LS but also many factors exert some influence on students' performance, making it harder to infer students' LS based only on fixed behavioural pattern rules, because students' behaviour and performance may be influenced by other factors besides LS. Some of these factors are pointed out by Haider et al. (2010), Graf et al. (2008), Kinshuk et al. (2009), Alfonseca et al. (2006), Graf et al. (2009), Messick (1976);

- it considers that the influence of each LS on students' behavior is unknown (Botsios et al., 2008);

- it considers that LS can change over time in an unpredictable way. These changes may be associated with other factors, such as knowledge domain, as analyzed by Jones et al. (2003);

- it considers that it is impossible to know the precision of the results obtained from self-assessment questionnaires (which may have inconsistencies; Price, 2004; Roberts and Erdos, 1993; Castillo et al., 2005);

- it eliminates the necessity to discover students' behavioural patterns, considering that it is hard or impossible to obtain such patterns, considering that students with the same learning styles preferences may, sometimes, act differently, taking into account the concept of tendencies, which means that even a learner with, e.g., a strong active LS can act sometimes in a reflective way (Graf and Kinshuk, 2009);

- it is uncoupled from any Learning Management System (LMS), being independent from any specific students' actions in a specific system, as it always occurs in traditional approaches (García et al., 2007; Graf and Liu, 2008);

- it takes into account the dynamic nature of LS, which may change when the knowledge domain changes (Kelly and Tangney, 2005) or naturally evolve over time (Messick, 1976);

- it eliminates the necessity of using complex machine learning techniques, which are difficult to implement and may bring problems such as the complications related to concept drift and concept shift, as exposed by Castilho et al. (2005);

- it eliminates the necessity of using drift-detection methods and dealing with concept drift and concept shift, which are automatically handled by the approach described in this paper.

Our approach is based on the Felder and Silverman Learning Styles Model (FSLSM). The next section presents important aspects of FSLSM to our work.

\section{Learning Styles}

LS are defined as the characteristics, strengths and preferences in the way people receive and process information (Felder and Silverman, 1988). It refers to the fact that each student has its own particular method or set of strategies when learning. A LS model classifies students according to the way they learn. A lot of LS models have been proposed, such as Kolb et al. (1984), Honey and Mumford (1992), Entwistle (1981), Pask (1976), Felder and Silverman (1988; FSLSM). Each one of these models describes different aspects in which students prefer to learn. 
Graf and Kinshuk (2009) point out that the FSLSM is one of the most frequently used in AES (Brusilovsky, 2001). Besides, Kuljis and Liu (2005) claim that FSLSM is the most appropriate model for the implementation of AES. According to Kinshuk et al. (2009), FSLSM combines the main models, such as Kolb et al. (1984), Pask (1976) and the Myers-Briggs indicator (Myers, 1957).

According to Graf and Kinshuk (2009, 2010a), the FSLSM uses the concept of dimensions, and therefore describes LS more thoroughly. As proposed by Felder and Silverman (1988), each learner has a dominant preference in each of the four dimensions: processing (active/reflective); perception (sensitive/intuitive); input (visual/verbal); understanding (sequential/global). Each preference tells us about how a student learns best and the related pedagogical strategies for effective learning. According to FSLSM, each learner has a preference within the scope of each one of the four dimensions described above, which is measured on a scale from +11 to -11 . This feature makes it possible to describe the strength of the learners' preferences (Kinshuk et al., 2009).

As described by Graf et al. (2009), LS are considered to be flexible stable, which means that they are relatively stable but they can change over time. For instance, when learners train their weak LS. Furthermore, FSLSM is based on the concept of tendencies, which means that even learners with, e.g., a strong active LS can act sometimes in a reflective way (Graf and Kinshuk, 2009).

A very important characteristic of FSLSM for our work is that it uses scales to classify students instead of using defined types. In this way, the strength of each LS is finely measured (Felder and Silverman, 1988). Another important aspect of FSLSM is that it considers LS as tendencies and students may act differently in specific situations, that is, in a non-deterministic way, as pointed out by Kinshuk et al. (2009). Therefore, we can consider students' LS as probabilities in the four-dimensional FSLSM model, as depicted in the next section.

\section{Automatic Diagnoses of Learning Styles}

In this section, we will present in detail our stochastic approach for automatic and dynamic modeling of students' LS. Our approach uses information from the evaluation of students' performances for updating the SM frequently while students are using the system for learning. Therefore, LS preferences are dynamically and constantly revised and corrected when learning difficulties are detected, which leads to a fine-tuned SM with high accuracy. Our approach combines automatic and dynamic student modeling aspects, according to definitions presented by Graf and Kinshuk (2009).

We consider students' preferences as probabilities in the four-dimensional FSLSM model. Due to the probabilistic nature of LS in the FSLSM, our approach is based on probabilistic LS combinations (Franzoni and Assar, 2009). A LS combination (LSC) is a 4-tuple composed by one preference from each FSLSM dimension, as stated by Definition 4.1 .

Therefore, there are 16 possible LSC, which are elements of the set LSCs, as stated by Definition 4.2. 
Definition 4.1. Learning Styles Combination ( $L S C)$ LSC $=(a, b, c, d)$ where: $a$ is either "A" or " $\mathrm{R}$ "; $b$ is either "S" or "I"; $c$ is either "Vi" or "Ve"; $d$ is either "Seq" or "G", such that: "A" represents the Active LS; "R" represents the Reflective LS; "S" represents the Sensitive LS; "I" represents the Intuitive LS; "Vi" represents the Visual LS; "Ve" represents the Verbal LS; "Seq" represents the Sequential LS and "G" represents the Global LS.

Definition 4.2. Learning Styles Combinations (LSCs)

$\mathrm{LSCs}=\{(\mathrm{A}, \mathrm{S}, \mathrm{Vi}, \mathrm{Seq}),(\mathrm{A}, \mathrm{S}, \mathrm{Vi}, \mathrm{G}),(\mathrm{R}, \mathrm{S}, \mathrm{Vi}, \mathrm{Seq}),(\mathrm{R}, \mathrm{S}, \mathrm{Vi}, \mathrm{G}),(\mathrm{A}, \mathrm{S}, \mathrm{Ve}, \mathrm{Seq}),(\mathrm{A}, \mathrm{S}, \mathrm{Ve}, \mathrm{G})$, (R,S,Ve,Seq), (R,S,Ve,G), (A,I,Vi,Seq), (A,I,Vi,G), (R,I,Vi,Seq), (R,I,Vi,G),

(A,I,Ve,Seq), (A,I,Ve,G), (R,I,Ve,Seq), (R,I,Ve,G)\}

Specifically, we propose that in each learning session, students must interact with learning objects (LO; IEEE, 2010) that satisfy a specific LSC, relating LS characteristics to LO characteristics. The LSC to be considered during a learning session is stochastically generated according to students' LS preferences stored in SM. Which means that, in our approach, a LSC is a specific combination of four random variables (Papoulis et al., 2002). Therefore, in our approach, the SM describes the probability of four random variables: $a ; b ; c ; d$ considering Definition 4.1.

Hence, students' probable LS are stored in the SM as values in the interval $[0,1]$. Those values represent probabilities of preference in each FSLSM dimension. Therefore, students' LS are stored as probability distributions considering each FSLSM dimension. Considering this kind of model, students' LS are stored in SM according to Definition 4.3.

DEFINITION 4.3. Learning Styles (LS)

$\mathrm{LS}=\left\{\left(\operatorname{Pr}_{A}=x ; \operatorname{Pr}_{R}=1-x\right),\left(\operatorname{Pr}_{S}=y ; \operatorname{Pr}_{1}=1-y\right)\right.$,

$\left.\left.\operatorname{Pr}_{V i}=z ; \operatorname{Pr}_{V e}=1-z\right) ;\left(\operatorname{Pr}_{S e q}=w ; \operatorname{Pr}_{G}=1-w\right)\right\}$, where

$\operatorname{Pr}_{A}$ is the probability of the student's preference for the Active LS;

$\operatorname{Pr}_{R}$ is the probability of the student's preference for the Reflective LS;

$\operatorname{Pr}_{S}$ is the probability of the student's preference for the Sensitive LS;

$\operatorname{Pr}_{I}$ is the probability of the student's preference for the Initive LS;

$\operatorname{Pr}_{V i}$ is the probability of the student's preference for the Visual LS;

$\operatorname{Pr}_{V e}$ is the probability of the student's preference for the Verbal LS;

$\operatorname{Pr}_{S e q}$ is the probability of the student's preference for the Sequential $S$;

$\operatorname{Pr}_{G}$ is the probability of the student's preference for the Global LS.

Consequently, we have: $\operatorname{Pr}_{A}+\operatorname{Pr}_{R}=1 ; \operatorname{Pr}_{S}+\operatorname{Pr}_{I}=1 ; \operatorname{Pr}_{V i}+\operatorname{Pr}_{V e}=1 ; \operatorname{Pr}_{S e q}+$ $\operatorname{Pr}_{G}=1$. Initially, if the system doesn't have any assumption about students' LS, the SM is set with balanced preferences, as presented in Table 1, which means that the probabilities of preference for each LS in a dimension are equal (there are no preferences), considering that, initially, the SM doesn't have any information about how the student probably learns best.

If a psychometric instrument - like the ILS (Van Zwanenberg et al., 2000) - is used to initialize the SM, the system calculates the proportion of favorable answers to each LS. 
Table 1

Learning styles initially stored in the student model

\begin{tabular}{|c|c|c|c|c|c|c|c|}
\hline \multicolumn{8}{|c|}{ Learning Styles } \\
\hline \multicolumn{2}{|c|}{ Processing } & \multicolumn{2}{|c|}{ Perception } & \multicolumn{2}{|l|}{ Input } & \multicolumn{2}{|c|}{ Understanding } \\
\hline Act.(A) & Ref.(R) & Sen.(S) & Int.(I) & Vis.(Vi) & Ver.(Ve) & Seq. & Glo.(G) \\
\hline 0.50 & 0.50 & 0.50 & 0.50 & 0.50 & 0.50 & 0.50 & 0.50 \\
\hline
\end{tabular}

Table 2

Learning styles initially stored in the student model

\begin{tabular}{|c|c|c|c|c|c|c|c|}
\hline \multicolumn{8}{|c|}{ Learning Styles } \\
\hline \multicolumn{2}{|c|}{ Processing } & \multicolumn{2}{|c|}{ Perception } & \multicolumn{2}{|l|}{ Input } & \multicolumn{2}{|c|}{ Understanding } \\
\hline Act.(A) & Ref.(R) & Sen.(S) & Int.(I) & Vis.(Vi) & Ver.(Ve) & Seq. & Glo.(G) \\
\hline 0.28 & 0.72 & 0.09 & 0.91 & 0.45 & 0.55 & 0.82 & 0.18 \\
\hline
\end{tabular}

This calculation is done by (1), which divides by 11 the number of favorable answers to a LS $\left(A_{i}\right)$, considering that the ILS has 11 questions for each FSLSM dimension, totaling 44 questions. In (1), $i$ represents a LS in a FSLSM dimension, and $A_{i}$ represents the number of favorable answers to a $\mathrm{LS}$. $\operatorname{Pr}_{i}$ is the probability of preference for a LS by the student in a FSLSM dimension, according to Definition 4.3.

$$
\operatorname{Pr}_{i}=\frac{A_{i}}{11}
$$

An example would be if a student answers 3 questions favorable to the Active LS and 8 questions favorable to the Reflective LS, we have:

$$
\operatorname{Pr}_{A}=\frac{3}{11}=0.28 ; \quad \operatorname{Pr}_{R}=\frac{s}{11}=0.72 .
$$

Therefore, we store 0.28 for the Active LS and 0.72 for the Reflective LS in the SM, which indicates the probability of preference for each one of those LS by the student. In our probabilistic approach, that means that there is a probability of preference $\operatorname{Pr}_{A}=28 \%$ for the Active LS and a probability of preference $\operatorname{Pr}_{R}=72 \%$ for the Reflective LS by the student. Continuing the example, lets consider that the other answers resulted in:

$$
\begin{aligned}
& \operatorname{Pr}_{S}=\frac{1}{11}=0.09 ; \quad \operatorname{Pr}_{I}=\frac{10}{11}=0.91 ; \quad \operatorname{Pr}_{V i}=\frac{5}{11}=0.45 ; \\
& \operatorname{Pr}_{V e}=\frac{6}{11}=0.55 ; \quad \operatorname{Pr}_{S e q}=\frac{9}{11}=0.82 ; \quad \operatorname{Pr}_{G}=\frac{2}{11}=0.18 \text {. }
\end{aligned}
$$

Therefore, Table 2 presents the initial LS stored in the SM. 
Therefore, considering Table 2, the student probably is Reflective, Intuitive, Verbal and Sequential. In this context, one advantage of this approach is to stochastically consider all LSC according to the student's probable LS that may be inconsistent with the student's real LS, as pointed out in 2. As shown in Section 5, this characteristic allows for the effective discovery and the fine-tuning of the student's LS preferences. The LS stored in the SM are constantly updated throughout the course, as explained later in this section. Therefore, Table 3 presents a possible evolution of the SM presented in Table 2.

The SM presented in Table 3 represents a student with $35 \%$ probability of preference for the active LS and $65 \%$ probability of preference for the reflective LS; $17 \%$ probability of preference for the sensitive LS and $83 \%$ probability of preference for the intuitive LS; $89 \%$ probability of preference for the visual LS and $11 \%$ probability of preference for the verbal LS; 84\% probability of preference for the sequential LS and 16\% probability of preference for the global LS. Therefore, considering Table 3, the student probably is Reflective, Intuitive, Visual and Sequential. Comparing Table 3 with Table 2, we can notice that initially, the student was supposedly Verbal, and now the student is supposedly Visual. Therefore, it is important to reinforce that it is a probability and not a certainty.

Then, in this approach, students' LS diagnosis is a stochastic process, conceived by four concurrent Markov Chains (Meyn et al., 2009), depicted in Fig. 1 (considering the SM presented in Table 3), where each state represents a LS in a FSLSM dimension. In Fig. 1a, State 1 represents the active LS and State 2 represents the reflective LS. In Fig. 1b, State 1 represents the sensitive LS and State 2 represents the intuitive LS. In Fig. 1c, State 1 represents the visual LS and State 2 represents the verbal LS. In Fig. 1d, State 1 represents the sequential LS and State 2 represents the global LS.

As stated before, during each learning session of a course, students must interact with LO that satisfy a specific LSC, relating LS characteristics to learning objects characteristics. This LSC is stochastically created according to four concurrent Markov Chains, depicted in Fig 1, considering the student's probable LS (stored in the SM) as transition probabilities.

Therefore, the probabilities of occurrence of a state (a LS as part of a LSC) is described by Fig. 1, where the transition probabilities are directly obtained from the SM (see Table 3), without any additional computational cost.

In this way, one LS from each FSLSM dimension is selected - according to the occurrence of a state in each Markov Chain, given by Fig. 1 - to generate a LSC, which will dictate to the AES how adaptivity must be provided, relating to LS, during a learning session.

Table 3

Possible evolution of learning styles stored in the student model

\begin{tabular}{|c|c|c|c|c|c|c|c|}
\hline \multicolumn{8}{|c|}{ Learning Styles } \\
\hline \multicolumn{2}{|c|}{ Processing } & \multicolumn{2}{|c|}{ Perception } & \multicolumn{2}{|l|}{ Input } & \multicolumn{2}{|c|}{ Understanding } \\
\hline Act.(A) & Ref.(R) & Sen.(S) & Int.(I) & Vis.(Vi) & Ver.(Ve) & Seq. & Glo.(G) \\
\hline 0.35 & 0.65 & 0.17 & 0.83 & 0.89 & 0.11 & 0.84 & 0.16 \\
\hline
\end{tabular}




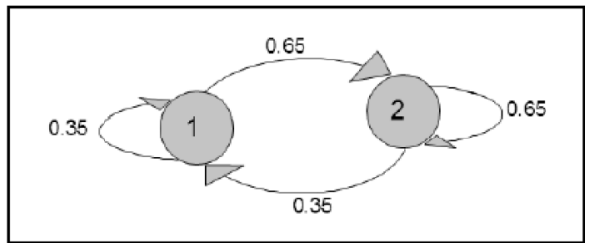

(a) processing: (1) active (2) reflective

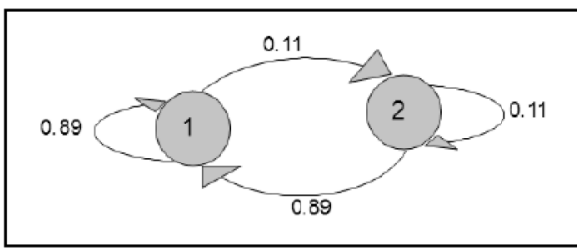

(c) input: (1) visual (2) verbal

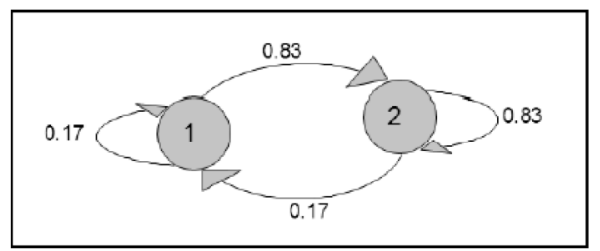

(b) perception: (1) sensitive (2) intuitive

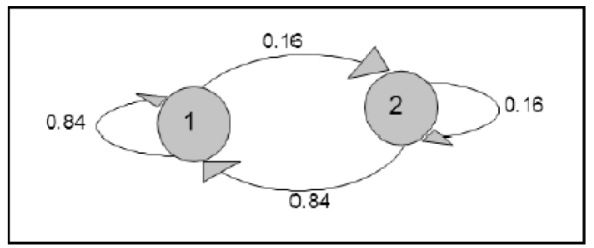

(d) understanding: (1) sequential (2) global

Fig. 1. A LSC is stochastically created according to a stochastic process modeled by four concurrent Markov Chains.

For example, if the LSC considered in the current learning session is $\mathrm{LSC}=(\mathrm{A}, \mathrm{S}, \mathrm{Vi}, \mathrm{Seq})$, the characteristics of the learning objects provided to a student must be related to the LS characteristics enclosed in the stochastically generated LSC, generated according to the SM.

Additionally, for the next learning session, we have a $35 \%$ probability of the Active LS appearing in the LSC against a $65 \%$ probability of the Reflective LS, because at this moment the student is supposedly Reflective, according to the SM. Analogously, we have a $17 \%$ probability of the Sensitive LS appearing in the LSC against a $83 \%$ probability of the Intuitive LS, because at this moment the student is supposedly Intuitive, according to the SM. However, we have to consider that these probabilities are constantly updated, because the SM is constantly being updated, as will be described. It is important to reinforce that these probabilities are directly obtained from the SM.

When a student shows a learning problem during a learning session (unsatisfactory performance), the LS stored in the SM, which appear in current LSC, are decremented, considering a probable inconsistency in these preferences. Students' preferences, which do not appear in current LSC, are incremented (reinforced), making them stronger, considering that the learning difficulties appeared because they were not present in the selected LSC. These updates are executed by the following rules (where A and B represents LS in a FSLSM dimension; $d_{i}$ indicates one of the four FSLSM dimensions; R indicates the reinforcement to be applied to the LS in the SM):

- $\mathrm{SM}\left[\mathrm{d}_{i}\right]_{A}$ - probability of preference for the LS $A$ stored in the SM, in dimension $i$, with $i=1 . .4$.

- $\operatorname{SM}\left[d_{i}\right]_{B}$ - probability of preference for the LS $B$ stored in the SM, in dimension $i$, with $i=1 . .4$.

- $\operatorname{LSC}\left[\mathrm{d}_{i}\right]-\mathrm{LS}$ in LSC related to the dimension $i$, with $i=1 . .4$. 


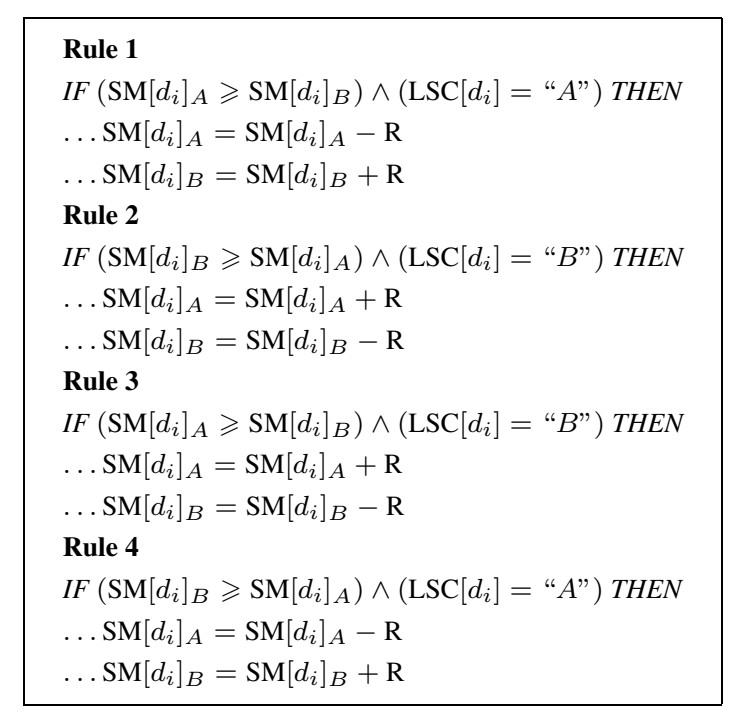

Rule 1 and Rule 2 decrease the distance between the LS (DLS) inside a dimension, while Rule 3 and Rule 4 increase the DLS inside a dimension, as shown in Fig. 2, in which A and B, in y-axis, represents a student's probable LS, according to Definition 4.3, during the learning process. The $\mathrm{x}$-axis represents the learning sessions of the learning process.

It is important to notice that when a learning problem is detected, all LS in the SM are updated by one of those rules. The reinforcement R, given by (2), is calculated considering the DLS inside a specific dimension in the SM, and the student's performance value (PFM) obtained on the learning session. DLS is calculated by (3). The reinforcement R is calculated for each FSLSM dimension, considering its specific DLS. The PFM is in the interval $[0,100]$ and the DLS is in the interval $[0,1]$.

$$
\begin{aligned}
& R=\frac{K}{\mathrm{PFM} \times \mathrm{DLS}} \\
& \mathrm{DLS}=\left|\mathrm{SM}\left[d_{i}\right]_{A}-\mathrm{SM}\left[d_{i}\right]_{B}\right| .
\end{aligned}
$$

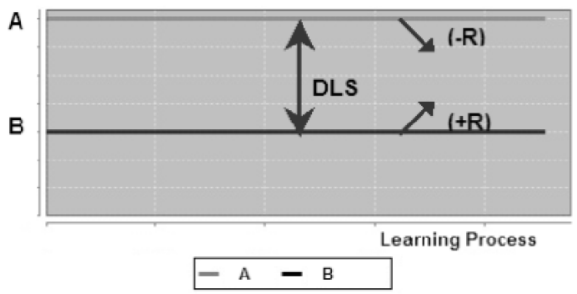

(a) Updating of LS by Rule 1 and Rule 2

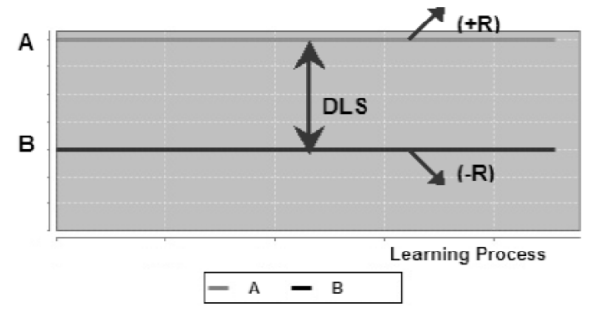

(b) Updating of LS by Rule 3 and Rule 4

Fig. 2. Updating of LS during the learning process. 
Therefore, while PFM is decreased, R is increased. And while DLS is increased, Ris decreased, where $\mathrm{K}$ is a constant. By observing the formula (2), we can see that if $\mathrm{K}$ has a high value, $\mathrm{R}$ becomes high, which produces abrupt changes in SM. This is not desirable, due to the uncertainty and non- deterministic aspect enclosed on the LS modeling process (e.g., when the probable LS in SM are already consistent with the student's real LS).

Furthermore, not only LS but also many factors exert influence on students' performances, making it harder to infer students' LS abruptly. On the other hand, if $\mathrm{K}$ has a low value, $\mathrm{R}$ becomes very low, which produces insignificant changes in the SM, taking a long time to remove inconsistencies from SM, resulting in an inefficient process. Thus, properly setting the value of $K$ is a very important point in this approach. We are using $K=10$, which was set empirically, through experiments. When PFM or DLS becomes very low, $R$ automatically becomes very high. In practice, it produces a very fast change of values in SM, whenever DLS close to 0 . This is necessary because when the ratio is $50 \%$ to $50 \%$ in the LS of the SM, the student's preference is still undercover, and the faster we discover it the faster the system can deliver content tailored to the student's real needs. This can be observed in all graphs of the experiments expounded in next section, and it is a desirable feature in our approach. The same fact occurs when PFM is very low. When it happens, the student may be facing high difficulty, due to poor personalization of the course, caused by inconsistencies in the SM. In this case, faster changes in SM are desirable, in order to correct the SM the sooner as possible. But, as stated before, not only LS but also many factors exert influence on students' performances, making it harder to infer students' LS abruptly. Therefore, the limit of $R$ is 0.05 (5\%), which was set empirically, through experiments.

It is well-known that a variety of factors should be taken into account for students' performance evaluation and learning problems detection, as pointed out in Dorça et al. (2009), Lopes et al. (2008). It's a complex problem and a lot of approaches have been proposed to solve it. For testing our approach without this complexity, we considered a simulated learning process, which is a stochastic process that infers students' performances, taking into account some aspects related to the impact of LS on learning processes, as depicted in Haider et al. (2010), Graf et al. (2008), Kinshuk et al. (2009), Alfonseca et al. (2006), Graf et al. (2009).

The main aspect of this simulated process is that when a student's real LS preference appears in the current LSC, learning becomes easier and the probability of success is increased. As pointed out by Graf et al. (2008), strong preferences produce stronger negative effects on students' performances when they are not satisfied by the teaching process, and this fact is considered by our students' performance simulation process (SPSP). The impact of LS strengths on students' performances is analyzed by Kinshuk et al. (2009). Results show that learners with strong preferences for a specific learning style have more difficulties in learning than learners with mild LS preferences. According to Kinshuk et al. (2009), this finding shows that learners with strong LS preferences can especially benefit from adaptivity.

These considerations are taken into account by the SPSP, which was developed to allow the experimentation of our approach. A probabilistic model was designed to imple- 
ment the non-deterministic aspect enclosed in students' performances, due to the large amount of facts that exert influence on them. This model is briefly explained hereafter.

Basically, the SPSP considers an increase of difficulty when a student's real LS (SRLS) doesn't appear in the LSC considered for providing adaptivity during a learning session.

Therefore, the SPSP knows the students' real LS, and does not know the student's probable LS (SPLS) stored in the SM. Therefore, the SM is not taken into account by SPSP to calculate the student's probability of failure, because, in reality, only SRLS exert influence on performance. Besides, SRLS may be different from SPLS (when the SM is initially inconsistent or becomes inconsistent during the learning process, as discussed before).

In this way, the SPSP can infer the degree of difficulty to be faced by the student during a learning session. Increasing the probability of failure also increases the level of difficulty. Therefore, considering the learning process as a non-deterministic process, which is influenced by many factors besides LS, the SPSP considers that the occurrence of inadequately adapted content may contribute to students' failure, but, cannot determine it.

In this context, SPSP increases the probability of failure $\left(\operatorname{Pr}_{\text {failure }}\right)$ by $15 \%$ for each learning style in the stochastically generated LSC (Definition 4.1) that doesn't represent the student's real LS. In this paper, this is called non-satisfied real preference (NSRP). Additionally, SPSP increases by $20 \%$ the previously calculated $\operatorname{Pr}_{\text {failure }}$, if at least one strong preference is not satisfied by the LSC during a learning session. This is called non-satisfied real strong preference (NSRSP). Furthermore, it increases by $10 \%$ the previously calculated $\mathrm{Pr}_{\text {failure }}$ if a moderate preference is not satisfied by the LSC during a learning session. This is called non-satisfied real moderate preference (NSRMP). Mild (or balanced) LS preferences don't cause an increase in the $\mathrm{Pr}_{\text {failure }}$, as previously calculated. If all real preferences appear in the stochastically generated LSC, and there is no occurrence of NSRP, then the SPSP takes into account a probability of failure equal to $15 \%$ (not only LS but also many factors exert some influence on students' performances). This inference model is presented below.

$$
\begin{aligned}
& \mathrm{Pr}_{\text {failure }}=\mathrm{NSRP} \times 0.15 \\
& \mathrm{IF}\left(\text { there is NSRSP) THEN } \mathrm{Pr}_{\text {failure }}=\operatorname{Pr}_{\text {failure }} \times 1.2 \text { (increase by } 20 \%\right) \\
& \text { ELSE IF (there is NSRMP) THEN } \mathrm{Pr}_{\text {failure }}=\mathrm{Pr}_{\text {failure }} \times 1.1 \text { (increase by } 10 \% \text { ) } \\
& \text { IF }\left(\operatorname{Pr}_{\text {failure }} \text { is equal to } 0\right) \text { THENPr } r_{\text {failure }}=0.15
\end{aligned}
$$

Then, SPSP generates a random number in the interval $[0,1]$. If this number is less than or equal to $\mathrm{Pr}_{\text {failure }}$, SPSP infers the occurrence of a learning problem (unsatisfactory performance, or failure). On the other hand, SPSP infers the occurrence of satisfactory performance. When a learning problem is detected, the LS stored in the SM are updated by the rules previously depicted in this section. While these updates are executed, the SM becomes more consistent and, consequently, adaptivity becomes more accurate. Therefore, the student's performance is improved (learning problems are gradually mitigated). 
We are aware that the probabilities values used by the SPSP's inference model should be particular to each student. But, considering observations by authors as Haider et al. (2010), Graf et al. (2008), Kinshuk et al. (2009), Alfonseca et al. (2006), Graf et al. (2009), we believe that those values are reasonable for experimentation. Simulation is a widespread and widely used technique for testing educational approaches and may bring advantages, as stated by Abdullah and Cooley (2002), Vanlehn et al. (1994), Vizcaino and du Boulay (2002), Virvou et al. (2003), Bravo and Ortigosa (2006), Mertz (1997), Meyn et al. (1996). The next section presents some experiments and their results.

\section{Evaluating the Proposed Approach}

\subsection{Methodology}

The evaluation of our approach was done through a set of experiments using computational simulation of the learning process, as pointed out in Section 4. Each experiment was repeated 20 times. Therefore, we could observe the process under different circumstances and identical conditions. It was possible to notice that the resulting sequences during an experiment were different, but the final results were very similar. So, the nondeterministic and convergence aspects intrinsic to the student modeling process were very clear to us.

For each experiment we set a different initial student's probable LS (SPLS), usually inconsistent with the student's real LS (SRLS) in the beginning of the learning process. In addition, we set the SRLS, used by the SPSP to infer the student's performance, as explained in Section 4. The SPSP needs to know the SRLS and its strengths (strong, moderate or balanced).

Four experiments are discussed in this section. One execution for each of the four experiments, and their results, are also shown in this section. The execution of an experiment finishes when the student achieves all learning goals. We considered 30 concepts to be learned by students and 6 cumulative cognitive levels (or categories) to be achieved in each concept, based on the Bloom's Taxonomy for Knowledge (Bloom and Krathwohl, 1956). Therefore, the simulated learning process, in these experiments, should have, at least, 180 learning sessions, or iterations, in order to achieve all learning goals $(30 \times 6=180)$.

The learning process is constituted by learning sessions. Each learning session represents an iteration of the simulated learning process. When students have a good performance during a learning session, their cognitive level in a concept evolves, until they reach the maximum cognitive level to the concept. When students fail, their cognitive level in the concept does not evolve. Therefore, the easier the learning process, the fewer iterations necessary to achieve all learning goals. And, the better adapted the content is, the easier the learning process is, as pointed out in Section 1.

For each experiment we show, graphically, how SPLS, stored in SM, are updated during the learning process. In each graph, the $\mathrm{x}$-axis shows the iterations of the learning process, and the y-axis shows the SPLS values throughout the learning process (multiplied by 100). The main goal was to observe how SPLS are gradually updated and 
fine-tuned along the iterations of the learning process. In the following experiments, the SRLS are fixed and the initial SPLS are different for each experiment. In the following experiments, we considered students with the following SRLS:

SRLS $=\{$ reflective (strong), sensitive (strong), visual (moderate), global (balanced) $\}$

\subsection{Experiment 1}

The SPLS were initialized as shown in Table 4. As it can be seen, the SPLS is initially inconsistent with the SRLS and doesn't express the student's preferences correctly, specifically in dimensions active/reflective and sensitive/intuitive. The main goal of our approach is to discover student's LS, making the SM consistent with the SRLS.

Figure 3 presents an execution of this experiment and shows how the SPLS were updated along the learning process. As it can be seen, during the learning process, the SPLS became consistent with the SRLS.

Table 4

SM - Experiment 1

\begin{tabular}{|c|c|c|c|c|c|c|c|}
\hline \multicolumn{8}{|c|}{ SPLS } \\
\hline \multicolumn{2}{|c|}{ Processing } & \multicolumn{2}{|c|}{ Perception } & \multicolumn{2}{|c|}{ Input } & \multicolumn{2}{|c|}{ Understanding } \\
\hline Act. & Ref. & Sen. & Int. & Vis. & Ver. & Seq. & Glo. \\
\hline 0.72 & 0.28 & 0.18 & 0.82 & 0.64 & 0.36 & 0.45 & 0.55 \\
\hline
\end{tabular}

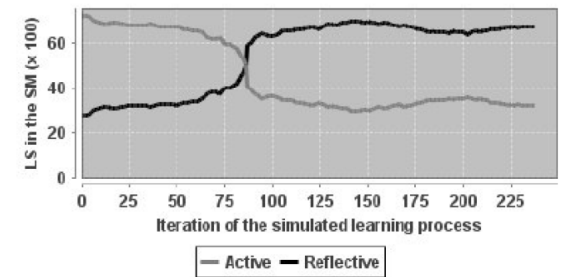

(a) Processing

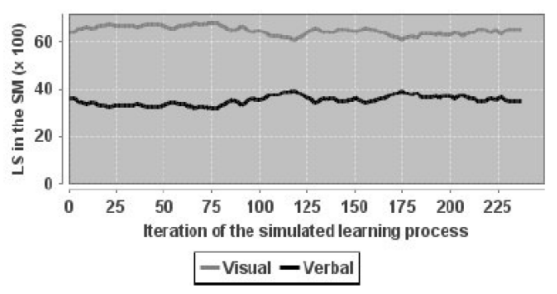

(c) Input

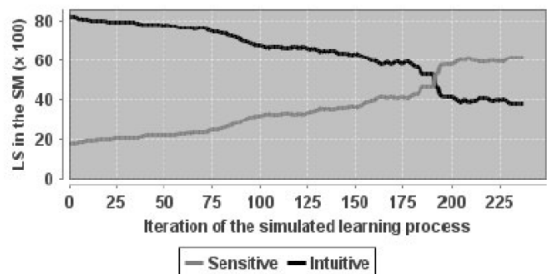

(b) Perception

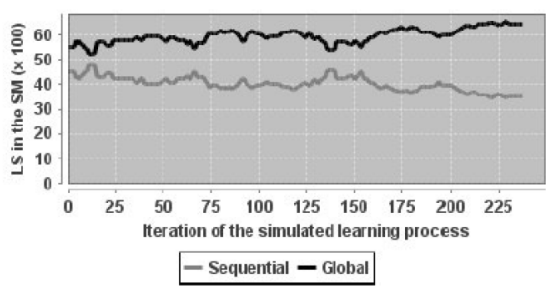

(d) Understanding

Fig. 3. Results from Experiment 1. 
In Fig. 3, Figs. 3a, 3b, 3c and 3d show the updating of SPLS in dimensions Processing, Perception, Input and Understanding respectively, during the simulated learning process. All repetitions of this experiment produced a SM consistent with the SRLS through a different path, due to the non-deterministic aspect of the student modeling process and performance evaluation.

\subsection{Experiment 2}

In this experiment, we consider the case in which there is no initial information available about SPLS, as reported by the SM shown in Table 5.

Figure 4 presents the results obtained from an execution of this experiment. In Fig. 4 , Figs. 4a, 4b, 4c and 4d show the updating of SPLS in dimensions Processing, Perception, Input and Understanding respectively, during the simulated learning process.

Figure 4 shows that less iterations were necessary than in Experiment 1. This occurred because inconsistencies in SM seem to be worse than the lack of initial information about

Table 5

SM - Experiment 2

\begin{tabular}{|c|c|c|c|c|c|c|c|}
\hline \multicolumn{8}{|c|}{ SPLS } \\
\hline \multicolumn{2}{|c|}{ Processing } & \multicolumn{2}{|c|}{ Perception } & \multicolumn{2}{|c|}{ Input } & \multicolumn{2}{|c|}{ Understanding } \\
\hline Act. & Ref. & Sen. & Int. & Vis. & Ver. & Seq. & Glo. \\
\hline 0.50 & 0.50 & 0.50 & 0.50 & 0.50 & 0.50 & 0.50 & 0.50 \\
\hline
\end{tabular}

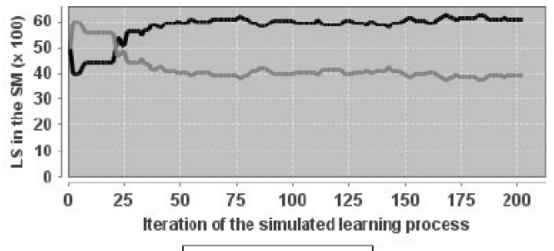

- Active - Reflective

(a) Processing

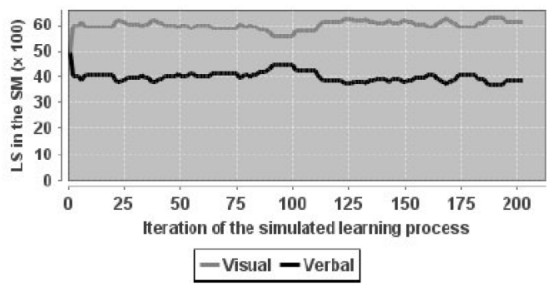

(c) Input

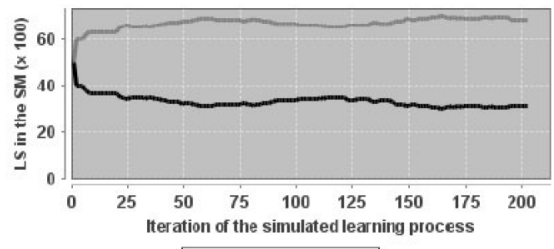

-Sensitive - Intuitive

(b) Perception

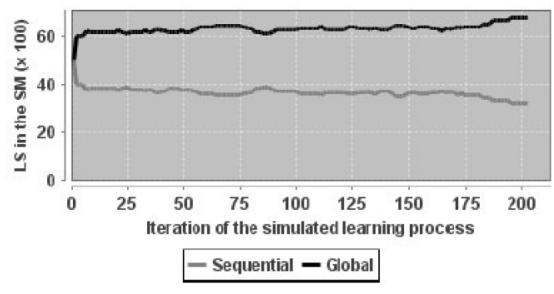

(d) Understanding

Fig. 4. Results from Experiment 2. 
the SPLS. When the system doesn't have any initial information available about SPLS, it discovers the SRLS faster and provides accurate adaptivity earlier, making the learning process easier.

Therefore, considering this approach, an AES doesn't have to apply a self-assessment questionnaire in order to initialize the SM. This feature allows eliminating possible initial inconsistencies in the SM, which may occur when using such questionnaires. All repetitions of this experiment produced a consistent SM.

\subsection{Experiment 3}

This experiment presents the case in which we reuse consistent SPLS, obtained from Experiment 2, in order to initialize the SM. The goal is to show how the SM is fine-tuned during the learning process. Table 6 shows the initial SM used in this experiment.

Figure 5 shows the results obtained from an execution of this experiment. In Fig. 5, Figs. 5a, 5b, 5c and 5d show the updating of SPLS in dimensions Processing, Perception,

Table 6

SM - Experiment 3

\begin{tabular}{|c|c|c|c|c|c|c|c|}
\hline \multicolumn{8}{|c|}{ SPLS } \\
\hline \multicolumn{2}{|c|}{ Processing } & \multicolumn{2}{|c|}{ Perception } & \multicolumn{2}{|c|}{ Input } & \multicolumn{2}{|c|}{ Understanding } \\
\hline Act. & Ref. & Sen. & Int. & Vis. & Ver. & Seq. & Glo. \\
\hline 0.39 & 0.61 & 0.55 & 0.44 & 0.66 & 0.34 & 0.38 & 0.62 \\
\hline
\end{tabular}

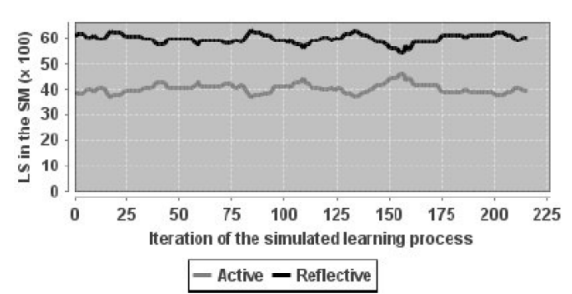

(a) Processing

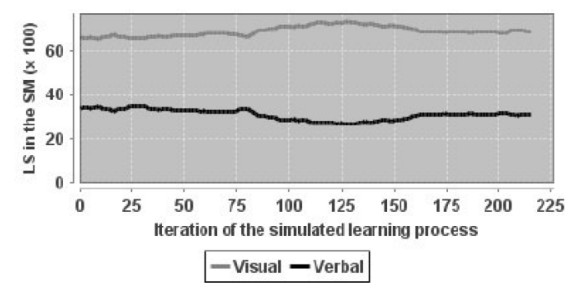

(c) Input

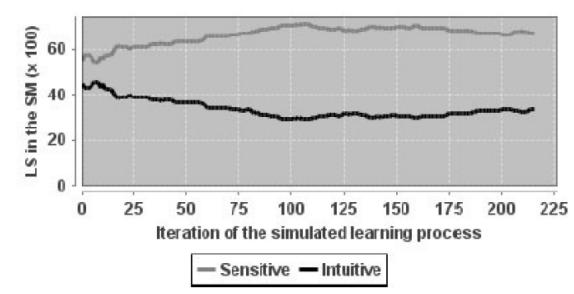

(b) Perception

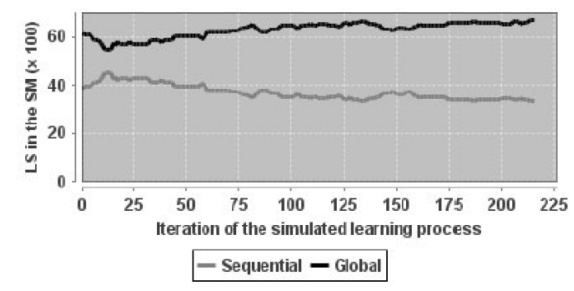

(d) Understanding

Fig. 5. Results from Experiment 3. 
Input and Understanding respectively, during the simulated learning process. As it can be seen, we had a considerable reduction of iterations, due to the initial consistency of the SM, which means that having precise information about students' LS and providing support to it during the learning process, results in great positive effects on students' performances, as pointed out in Section 1.

\subsection{Experiment 4}

This experiment considers the case in which all LS preferences, in the SM, are initially inconsistent, as shown in Table 7.

A result is shown in Fig. 6, in which Figs. 6a, 6b, 6c and 6d show the updating of SPLS in dimensions Processing, Perception, Input and Understanding respectively, during the simulated learning process.

Table 7

SM - Experiment 4

\begin{tabular}{|c|c|c|c|c|c|c|c|}
\hline \multicolumn{8}{|c|}{ SPLS } \\
\hline \multicolumn{2}{|c|}{ Processing } & \multicolumn{2}{|c|}{ Perception } & \multicolumn{2}{|c|}{ Input } & \multicolumn{2}{|c|}{ Understanding } \\
\hline Act. & Ref. & Sen. & Int. & Vis. & Ver. & Seq. & Glo. \\
\hline 0.70 & 0.30 & 0.30 & 0.70 & 0.30 & 0.70 & 0.70 & 0.30 \\
\hline
\end{tabular}

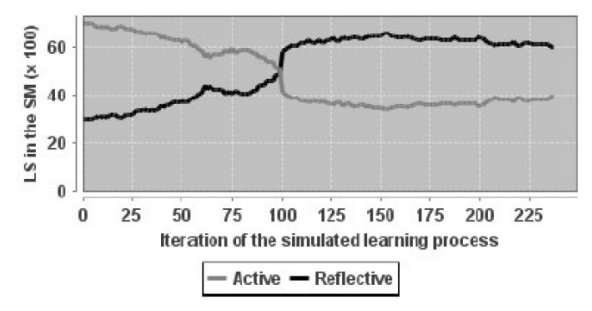

(a) Processing

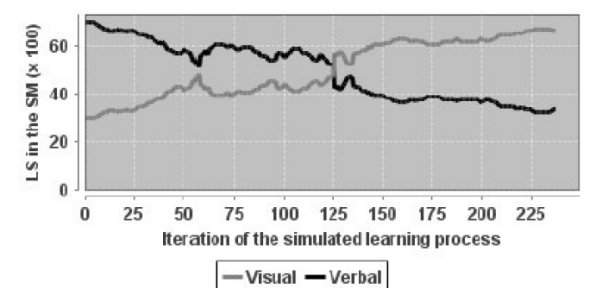

(c) Input

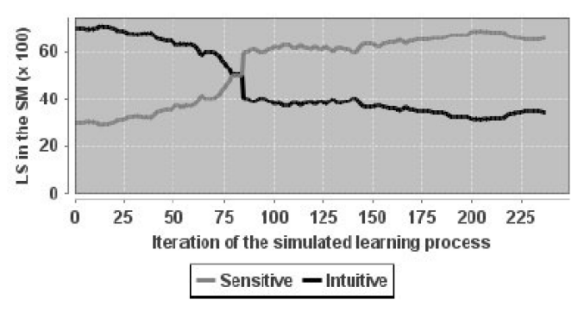

(b) Perception

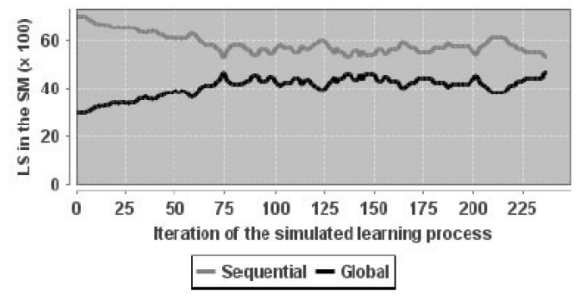

(d) Understanding

Fig. 6. Results from Experiment 4. 
Particularly, this repetition of the experiment didn't completely correct the SPLS in dimension Understanding, where the preference is balanced. But, the DLS was very minimized during the learning process in this dimension. This occurs because when students have a balanced preference, they are competent in both LS inside the dimension, and don't have a clear preference for one of them Coffield et al. (2009), making it difficult to discover their favorite LS.

Finally, we believe that the good results obtained from these experiments validate the proposed approach, which can be easily implemented in an existing LMS, like Moodle (2010), and tested with real students. The SPSP was a very important part of our work, because it allowed us to test, adjust and improve our approach since the very beginning, optimizing the development process.

These adjustments and improvements were mainly related to the rules depicted in Section 4, which determine the updates in the SPLS; and to the calculation of the reinforcement applied by those rules. Both are crucial points of our work, which are still being adjusted.

Therefore, without using simulation, it should be impossible to come up with this approach within reasonable time, due to the large amount of time necessary to do experiments with real students. A variety of experiments were performed - considering different SRLS and SPLS - and some of them have been exposed in this section. Next section points out some conclusions and future work.

\section{Conclusions and Future Work}

AES has been considered a promising approach to increase the efficiency in computeraided learning. A necessary characteristic in this approach is the precise, dynamic and continuous identification of students' LS in order to provide well-adapted learning experiences. In this context, one challenge is the development of systems able to efficiently acquire students' LS preferences.

The information about students' LS preferences, acquired by psychometric instruments, encloses some degree of uncertainty (Price, 2004; Roberts and Erdos, 1993). Furthermore, in most of the existing approaches, the assumptions about students' LS, once acquired, are no longer updated.

In this context, this work presents a new approach to automatically detect and precisely adjust students' LS preferences, based on the non-deterministic and non-stationary aspects of LS (Graf and Kinshuk, 2009). Because of the probabilistic and dynamic factors enclosed on students' LS modeling, our approach gradually and constantly modifies the SM using a set of rules that detect which LS should be adjusted at a specific point of the learning process, considering the student's performance. In this way, the SM converges to the SRLS, considering fine-tuned strengths, as showed in Section 5.

Finally, the proposed approach solves some important problems ignored by most of the analyzed approaches, and brings advantages, due to specific points, as shown in Section 2. The validation of our model was done through SPSP, which takes into account 
how LS preferences exert influence on students' performances, as described by some researchers, e.g., Haider et al. (2010), Graf et al. (2008), Kinshuk et al. (2009), Alfonseca et al. (2006), Graf et al. (2009).

The evaluation of AES is a difficult task, as pointed out in Bravo and Ortigosa (2006). Therefore, testing our approach through simulation was vital, due to the time and human resources needed to test it with real students. Now that we have achieved good results through simulation, we feel confident to implement our approach in an existing LMS, like SIMEduc (Dorça et al., 2003) and Moodle (2010), and test it with real courses and real students, as a future work. In order to achieve this goal, we are working on the development of function able to efficiently map LO characteristics to students' LS.

\section{References}

Abdullah, S.C., Cooley, R.E. (2002). Using Simulated Students to Evaluate an Adaptive Testing System. Alfonseca, E., Carro, R.M., Martín, E., Ortigosa, A., Paredes, P. (2006). The impact of learning styles on student grouping for collaborative learning: a case study. User Modeling and User-Adapted Interaction, 16(3), 377401.

Bloom, B.S., Krathwohl, D.R. (1956). Taxonomy of Educational Objectives: The Classification of Educational Goals. Handbook I: Cognitive domain. 64-81.

Botsios, S., Georgiou, D., Safouris, N. (2008). Contributions to adaptive educational hypermedia systems via on-line learning style estimation. Educational Technology \& Society, 12(4), 322-339.

Bravo, J., Ortigosa, A. (2006). Validating the evaluation of adaptive systems by user profile simulation. In: Proceedings of Workshop Held at the Fourth International Conference on Adaptive Hypermedia and Adaptive Web-Based Systems (AH2006), 479-483.

Brusilovsky, P. (2001). Adaptive educational hypermedia. In: International PEG Conference, 8-12.

Cabada, R.Z., Estrada, M.L.B., Garcia, C.A.R. (2009). A fuzzy-neural network for classifying learning styles in a Web 2.0 and mobile learning environment. In: Web Congress, LE-WEB'09, Latin American, 177-182.

Carmona, C., Castillo, G., Millán, E. (2007). Discovering student preferences in e-learning. In: Proceedings of the International Workshop on Applying Data Mining in e-Learning.

Carmona, C., Castillo, G. (2008). Designing a dynamic bayesian network for modeling students learning styles. In: Eighth IEEE International Conference on Advanced Learning Technologies, IEEE, 346-350.

Castillo, G., Gama, J., Breda, A.M. (2005). An adaptive predictive model for student modeling. In: Advances in Web-based Education: Personalized Learning Environments, 70-92.

Coffield, F., Moseley, D., Hall, E., Ecclestone, K. (2009). Learning Styles and Pedagogy in Post-16 Learning: A Systematic and Critical Review, National Centre for Vocational Education Research (NCVER).

De Bra, P., Smits, D., Stash, N. (2006). Creating and delivering adaptive courses with AHA! Innovative Approaches for Learning and Knowledge Sharing, 21-33.

Dorça, F.A., Lopes, C.R., Fernandes, M.A., Lopes, R.S. (2009). Adaptativity supported by neural networks in web-based educational systems. Journal of Education, Informatics and Cybernetics (JEIC), 1.

Dorça, F.A., Lopes, C.R., Fernandes, M.A. (2003). A multiagent architecture for distance education systems. In: Advanced Learning Technologies. Proceedings of the 3rd IEEE International Conference, 368-369.

Entwistle, N. (1981). Styles of Learning and Teaching, Wiley Chichester.

Felder, R.M., Silverman, L.K. (1988). Learning and teaching styles in engineering education. Engineering Education, 78(7), 674-681.

Franzoni, A.L., Assar, S. (2009). Student learning styles adaptation method based on teaching strategies and electronic media. Educational Technology \& Society, 12(4), 15-29.

García, P., Amandi, A., Schiaffino, S., Campo, M. (2007). Evaluating Bayesian networks' precision for detecting students' learning styles. Computers \& Education, 49(3), 794-808.

Graf, S., Kinshuk, C.I. (2009). Advanced adaptivity in learning management systems by considering learning styles. In: Proceedings of the 2009 IEEE/WIC/ACM International Joint Conference on Web Intelligence and Intelligent Agent Technology, Vol. 3, IEEE Computer Society, 235-238. 
Graf, S., Kinshuk, C.I. (2010a). A flexible mechanism for providing adaptivity based on learning styles in learning management systems. In: 10th IEEE International Conference on Advanced Learning Technologies, IEEE, 30-34.

Graf, S., Kinshuk, C.I. (2010b). Using cognitive traits for improving the detection of learning styles. In: Database and Expert Systems Applications (DEXA), 74-78.

Graf, S., Lin, T. (2007). Analysing the relationship between learning styles and cognitive traits. In: Advanced Learning Technologies, Seventh IEEE International Conference, 235-239.

Graf, S., Liu, T.C. (2008). Identifying learning styles in learning management systems by using indications from students' behaviour. In: Advanced Learning Technologies, ICALT'08, Eighth IEEE International Conference, 482-486.

Graf, S., Liu, Tzu-Chien, Kinshuk. Interactions between students learning styles, achievement and behaviour in mismatched courses. In: Proceedings of the International Conference on Cognition and Exploratory Learning in Digital Age (CELDA 2008), IADIS International Conference, 223-230.

Graf, S., Lan, C.H., Liu, T.C. (2009). Investigations about the effects and effectiveness of adaptivity for students with different learning styles. In: Ninth IEEE International Conference on Advanced Learning Technologies, $415-419$.

Graf, S., Kinshuk, Zhang, Q., Maguire, P., Shtern, V. (2010). An architecture for dynamic student modelling of learning styles in learning systems and its application for adaptivity. In: IADIS International Conference on Cognition and Exploratory Learning in Digital Age (CELDA 2010), 103-110.

Haider, M.T.U., Sinha, A.K., Chaudhary, B.D. (2010). An investigation of relationship between learning styles and performance of learners. International Journal of Engineering Science and Technology, 2(7), 28132819.

Honey, P., Mumford, A. (1992). The manual of Learning Styles.

IEEE.LOM (Learning Object Metadata). (2010). IEEE Learning Technology Standards Committee. http://ltsc. ieee.org/wg12/index.html.

Jones, C., Reichard, C., Mokhtari, K. (2003). Are students learning styles discipline specific? Community College Journal of Research and Practice, 27(5), 363-375.

Kelly, D., Tangney, B. (2005). First aid for you: getting to know your learning style using machine learning. In: Advanced Learning Technologies, ICALT, Fifth IEEE International Conference, 1-3.

Kinshuk, Liu, T.C., Graf, S. Coping with mismatched courses: students' behaviour and performance in courses mismatched to their learning styles. Educational Technology Research and Development, 57(6), 739-752.

Kolb, D.A. Experiential Learning: Experience as the Source of Learning and Development. Prentice-Hall Englewood Cliffs, NJ.

Kuljis, J., Liu, F. (2005). A comparison of learning style theories on the suitability for elearning. In: Proceedings of the IASTED Conference on Web Technologies, Applications, and Services, 191-197.

Lopes, R.S., Dorça, F.A., Fernandes, M.A., Lopes, C.R. (2008). Um sistema de avaliação em EAD baseado em lógica Fuzzy. In: Simpósio Brasileiro de Informática na Educação, 30-34.

Mertz, J.S. (1997). Using a simulated student for instructional design. International Journal of Artificial Intelligence in Education (IJAIED), 8, 116-141.

Messick, S. (1976). Personal styles and educational options. Individuality in Learning, 327-368.

Meyn, S.P., Tweedie, R.L., Glynn, P.W. (1996). Markov Chains and Stochastic Stability, Springer, London.

Meyn, S.P., Tweedie, R.L., Glynn, P.W. (2009). Markov Chains and Stochastic Stability, Vol. 2, Cambridge University Press Cambridge.

Moodle. (2010). http: / / www. moodle.org/.

Myers, I.B. (1957). The Myers-Briggs Type Indicator. Consulting Psychologists Press Palo Alto, CA. .

Papoulis, A., Pillai, S.U., Unnikrishna, S. (2002). Probability, Random Variables, and Stochastic Processes, Vol. 73660116, McGraw-Hill New York.

Pask, G. (1976). Styles and strategies of learning. British Journal of Educational Psychology.

Price, L. (2004). Individual differences in learning: Cognitive control, cognitive style, and learning style. Educational Psychology, 24(5), 681-698.

Roberts, M.J., Erdos, G. (1993). Strategy selection and meta-cognition. Educational Psychology, 13(3), 259266.

Zwanenberg, N. V., Wilkinson, L.J., Anderson, A. (2000). Felder and Silverman's index of learning styles and Honey and Mumford's learning styles questionnaire: how do they compare and do they predict academic performance? Educational Psychology, 20(3), 365-380. 
Vanlehn, K., Ohlsson, S., Nason, R. (1994). Applications of simulated students: an exploration. Journal of Artificial Intelligence in Education, 5, 135-135.

Virvou, M., Manos, K., Katsionis, G. (2003). An evaluation agent that simulates students' behaviour in intelligent tutoring systems. In: Systems, Man and Cybernetics, IEEE International Conference, Vol. 5, 48724877.

Vizcaino, A., du Boulay, B. (2002). Using a Simulated Student to Repair Difficulties in Collaborative Learning. Zatarain, R., Barrón-Estrada, L., Reyes-García, C., Reyes-Galaviz, O. (2010). Applying intelligent systems for modeling students' learning styles used for mobile and web-based systems. Soft Computing for Intelligent Control and Mobile Robotics, 3-22.

Zatarain-Cabada, R., Barrón-Estrada, M., Zepeda-Sánchez, L., Sandoval, G., Osorio-Velazquez, J., UriasBarrientos, J. (2009). A Kohonen network for modeling students' learning styles in web 2.0 collaborative learning systems. In: MICAI, Advances in Artificial Intelligence, 512-520.

F.A. Dorça is a PhD student at Faculty of Electrical Engineering (FEELT) at Federal University of Uberlandia (UFU), Brazil. ME in computer science (2004) at Faculty of Computer Science (FACOM) at UFU and BS in computer science (2000) at FACOM/UFU. Currently, he is an assistant professor at FACOM/UFU, and member of the Artificial Intelligence Laboratory at FEELT/UFU. He has experience in computer science, with emphasis on artificial intelligence, acting on the following topics: distance education, adaptive educational systems, cognitive psychology, dynamic student modeling, neural networks, genetic algorithms, genetic programming, software engineering.

L.V. Lima is an adjunct professor at Faculty of Electrical Engineering (FEELT) at Federal University of Uberlandia (UFU), Brazil. He is BS in electrical engineering at FEELT/UFU (1983), MS in Electrical Engineering at FEELT/UFU (1988) and PhD in electrical engineering at the University of São Paulo (USP-POLI) (1998). Conducts research and develops products in process automation in electrical engineering, automotive products, sound engineering (computer music), distance education and biomedical engineering at the artificial intelligence laboratory at FEELT/UFU.

M.A. Fernandes is BS in mathematics at Faculty of Mathematics (FAMAT) at the Federal University of Uberlandia (UFU), Brazil (1985), MS in systems engineering and computing at Federal University of Rio de Janeiro (UFRJ), Brazil (1989) and PhD in systems engineering and computer science at UFRJ (1996). She is currently an adjunct professor at Faculty of Computer Science (FACOM) at UFU. She has experience in computer science, with emphasis on computer methods and techniques, acting on the following topics, at the Artificial Intelligence Research Group FACOM/UFU: distance education, genetic algorithms, petri nets, synthesis of operating procedures, planning, hybrid systems.

C.R. Lopes is BS in electrical engineering at Faculty of Electrical Engineering (FEELT) at Federal University of Uberlandia (UFU) (1984), MS in electrical engineering at FEELT/UFU (1987) and PhD in electrical engineering at the University of São Paulo (USP) (1998). He is currently an associate professor at Faculty of Computer Science (FACOM) at UFU, and member of the Artificial Intelligence Research Group at FACOM/ UFU. He has experience in computer science, with emphasis on computer methods and techniques, acting on the following topics: artificial intelligence, planning, robotics, distance education. 


\section{Stochastinis metodas studentu mokymosi stiliu automatiniam ir dinaminiam modeliavimui adaptyviose mokymo sistemose}

Fabiano Azevedo DORÇA, Luciano Vieira LIMA, Márcia Aparecida FERNANDES, Carlos Roberto LOPES

Siekiant pagerinti studentu mokymosi rezultatus, adaptyvi mokymo sistema turi turèti informaciją, kuriuo atveju asmuo mokosi geriausiai. Šiame straipsnyje pristatomas novatoriškas studentu mokymosi modeliavimas taikant tikimybinị mokymosi stilių derinimą. Eksperimentai parodè, kad šiuo metodu galima automatiškai aptikti ir tiksliai reguliuoti studentu mokymosi stilius, pagrịstus nedeterministiniais ir nestacionariais mokymosi stiliu aspektais. Kadangi tikimybiniai ir dinaminiai aspektai yra įdèti ị automatinị mokymosi stiliu aptikimą, autoriu pasiūlytas metodas palaipsniui ir nuolat reguliuoja studentu mokymosi modelį, remdamasis studentu pasiekimais, taip gaunamas gerai suderintas studentu mokymosi modelis. Atlikus eksperimentus buvo gauti geri rezultatai, kai kurie iš jų aptariami šiame straipsnyje. 


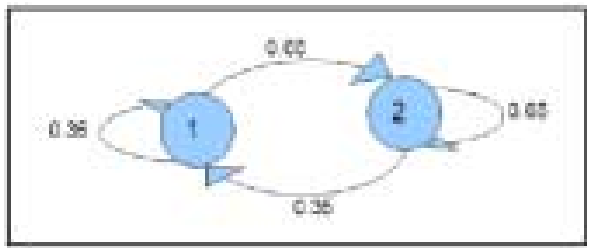

(a) processing: (1) active (2) rellective

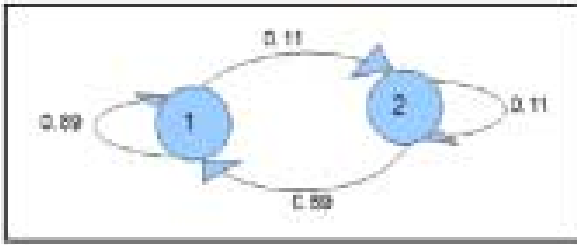

(c) input: (1) vistal (2) vertal

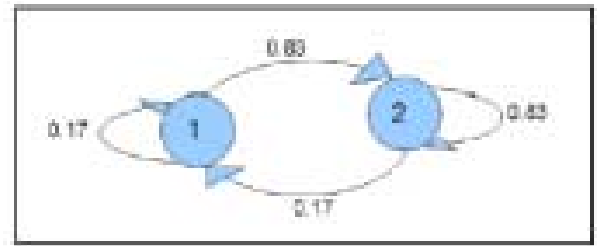

(b) perception: (1) sensitive (2) intuitive

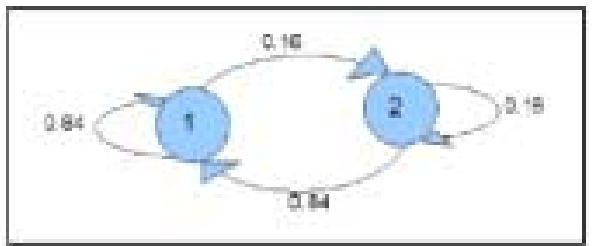

(d) understanding: (1) sequential (2) global

Fig. 1. A LSC is stochastically created according to a stochastic process modeled by four concurrent Markov Chains.

For example, if the LSC considered in the current learning session is $\mathrm{LSC}=(\mathrm{A}, \mathrm{S}, \mathrm{Vi}, \mathrm{Seq})$, the characteristics of the learning objects provided to a student must be related to the LS characteristics enclosed in the stochastically generated LSC, generated according to the SM.

Additionally, for the next learning session, we have a 35\% probability of the Active LS appearing in the LSC against a $65 \%$ probability of the Reflective LS, because at this moment the student is supposedly Reflective, according to the SM. Analogously, we have a $17 \%$ probability of the Sensitive LS appearing in the LSC against a $83 \%$ probability of the Intuitive LS, because at this moment the student is supposedly Intuitive, according to the SM. However, we have to consider that these probabilities are constantly updated, because the SM is constantly being updated, as will be described. It is important to reinforce that these probabilities are directly obtained from the SM.

When a student shows a learning problem during a learning session (unsatisfactory performance), the LS stored in the SM, which appear in current LSC, are decremented, considering a probable inconsistency in these preferences. Students' preferences, which do not appear in current LSC, are incremented (reinforced), making them stronger, considering that the learning difficulties appeared because they were not present in the selected LSC. These updates are executed by the following rules (where A and B represents LS in a FSLSM dimension; $d_{i}$ indicates one of the four FSLSM dimensions; R indicates the reinforcement to be applied to the LS in the SM):

- $\mathrm{SM}\left[\mathrm{d}_{i}\right]_{A}$ - probability of preference for the LS $A$ stored in the SM, in dimension $i$, with $i=1 . .4$.

- $\operatorname{SM}\left[d_{i}\right]_{B}$ - probability of preference for the LS $B$ stored in the SM, in dimension $i$, with $i=1 . .4$.

- $\operatorname{LSC}\left[\mathrm{d}_{i}\right]-\mathrm{LS}$ in LSC related to the dimension $i$, with $i=1 . .4$. 


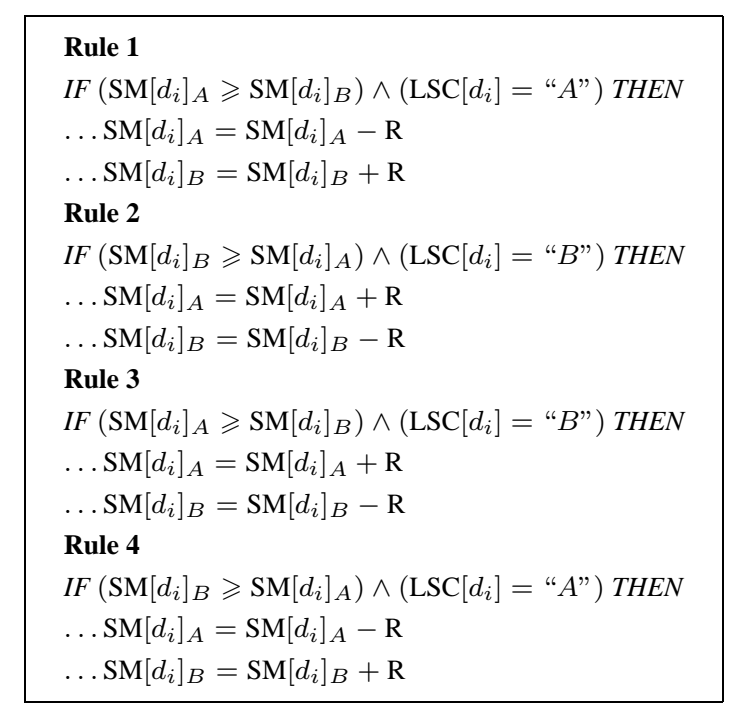

Rule 1 and Rule 2 decrease the distance between the LS (DLS) inside a dimension, while Rule 3 and Rule 4 increase the DLS inside a dimension, as shown in Fig. 2, in which A and B, in y-axis, represents a student's probable LS, according to Definition 4.3, during the learning process. The $\mathrm{x}$-axis represents the learning sessions of the learning process.

It is important to notice that when a learning problem is detected, all LS in the SM are updated by one of those rules. The reinforcement R, given by (2), is calculated considering the DLS inside a specific dimension in the SM, and the student's performance value (PFM) obtained on the learning session. DLS is calculated by (3). The reinforcement R is calculated for each FSLSM dimension, considering its specific DLS. The PFM is in the interval $[0,100]$ and the DLS is in the interval $[0,1]$.

$$
\begin{aligned}
& R=\frac{K}{\mathrm{PFM} \times \mathrm{DLS}}, \\
& \mathrm{DLS}=\left|\mathrm{SM}\left[d_{i}\right]_{A}-\mathrm{SM}\left[d_{i}\right]_{B}\right| .
\end{aligned}
$$

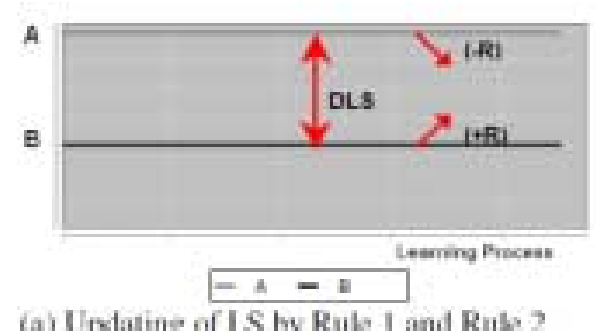

(a) Updating of LS by Rule I and Rube 2

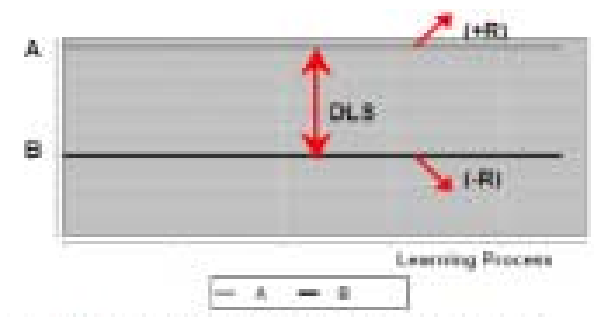

(b) Updating of LS by Rule 3 and Rule 4

Fig. 2. Updating of LS during the learning process. 